\title{
The influence of age and weaning on permeability of the gastrointestinal tract in Holstein bull calves
}

\author{
K. M. Wood, ${ }^{*}$ S. I. Palmer, ${ }^{*}$ M. A. Steele, † J. A. Metcalf, $\ddagger$ and G. B. Penner ${ }^{* 1}$ \\ *Department of Animal and Poultry Science, University of Saskatchewan, Saskatoon, Canada, S7N 5A8 \\ †Department of Agriculture, Food and Nutritional Sciences, University of Alberta, Edmonton, Canada, T6G 2P5 \\ ¥Nutreco Canada AgResearch, Guelph, Ontario, Canada, N1G 4T2
}

\section{ABSTRACT}

Fourteen Holstein bull calves were used in a randomized complete block design to investigate the effect of calf age and weaning on permeability of the gastrointestinal tract (GIT). Calves were randomly assigned to 1 of 2 treatments: (1) a weaning protocol that was initiated on d 35 ; WN; $\mathrm{n}=7$ ), or (2) a control treatment where calves were not weaned $(\mathrm{CON} ; \mathrm{n}=7)$. Calves were bottle-fed milk replacer $(150 \mathrm{~g} / \mathrm{L})$, in 3 equal portions/d targeting $15 \%$ of their body weight (BW) in liquid milk intake [approximately $21.1 \mathrm{~g} / \mathrm{kg}$ of $\mathrm{BW} / \mathrm{d}$, dry matter (DM) basis]. On d 35, the amount of milk replacer offered to WN calves was reduced to $7.5 \%$ of BW for $7 \mathrm{~d}$ before calves were weaned on $\mathrm{d} 42$. On d 14, 28, and 42, calves were orally dosed with $500 \mathrm{~mL}$ of Cr-EDTA (179 mM Cr-EDTA solution) and housed in a metabolism crate to enable total urine collection and determination of total urinary Cr recovery as an indicator of total-tract permeability. On d 44, calves were killed and tissues from the rumen, omasum, duodenum, jejunum, ileum, cecum, and proximal and distal colon were collected, rinsed, and transported in buffer solution $\left(\mathrm{pH} 7.4\right.$ at $\left.38.5^{\circ} \mathrm{C}\right)$. Tissues were incubated in Ussing chambers under short-circuit conditions with buffer solutions designed to mimic the mucosal and serosal energy source that would be available in vivo (glucose for tissues from the small intestine and shortchain fatty acids for tissues that would be exposed to fermentation; rumen, omasum, and large intestinal tissues). The serosal to mucosal flux of ${ }^{14} \mathrm{C}$-mannitol and ${ }^{3} \mathrm{H}$-inulin was measured for each region. Although we detected treatment $\times$ period interactions for BW and starter intake, dietary treatments did not differ within a week. Overall, the time that ruminal $\mathrm{pH}$ was $<5.5$ was less before weaning than after weaning. We observed a differential response for the appearance of $\mathrm{Cr}$

Received January 28, 2015.

Accepted June 28, 2015 .

${ }^{1}$ Corresponding author: greg.penner@usask.ca in urine for $\mathrm{WN}$ and $\mathrm{CON}$ calves, where the appearance of $\mathrm{Cr}(\mathrm{mg} / 48 \mathrm{~h})$ in urine decreased for both treatments from d 14 to 28 , but increased from d 28 to 42 for WN, whereas $\mathrm{Cr}$ appearance continued to decrease for CON. The flux of mannitol and inulin did not differ between treatments but did differ among region of the GIT, with rumen, duodenum, and jejunum having the greatest permeability. These data suggest that permeability of the GIT decreases with age but weaning may disrupt this process. The rumen, duodenum, and jejunum appear to be the regions with greatest permeability.

Key words: calf, gastrointestinal tract, permeability, Ussing chamber, weaning

\section{INTRODUCTION}

The postnatal period up to and through weaning is critical for dairy calves. For example, a recent study demonstrated that preweaning ADG, driven by greater consumption of milk replacer, was positively associated with first-lactation milk yield (Soberon et al., 2012). This period also represents a time when calves are susceptible to infectious disease. In fact, the leading cause of mortality and morbidity in calves during the first weeks of life in North America is diarrhea (NAHMS, 2007) caused by pathogenic infections of the gastrointestinal tract (GIT). As mortality and incidence of health events in calves remain high on dairy farms in North America, an improved understanding of this phase in calf development can lead to opportunities to enhance calf health and lifetime productivity.

Rearing programs for dairy calves have been designed to promote adequate DMI as a mechanism to stimulate development of the ruminal epithelium and minimize the reduction in growth at weaning (NRC, 2001). It should be recognized that weaning also results in a major shift in the site of nutrient digestion, from the intestine to the reticulo-rumen, and correspondingly the primary energy source changes [short-chain fatty acids (SCFA) and microbial protein vs. glucose, galactose, and milk fat and protein]. It could be expected that 
these changes may compromise gastrointestinal barrier function (Wijtten et al., 2011) due to low ruminal $\mathrm{pH}$ at weaning (Laarman et al., 2012) and that short-term reductions in nutrient provision reduce total-tract barrier function in cattle (Gaebel et al., 1993; Gäbel and Aschenbach, 2002; Zhang et al., 2013). However, only one study known to us has evaluated barrier function in Holstein calves in response to weaning (Malmuthuge et al., 2013). In that study, the mRNA expression of toll-like receptor-2 decreased and the expression of occludin and claudin- 4 increased in rumen tissue collected from calves weaned relative to their nonweaned comparatives. It is not clear whether these changes in mRNA expression correspond to changes in innate immune system responsiveness and permeability of the gastrointestinal tract. Moreover, it is not clear how calf age affects intestinal permeability.

Although rumen development is often evaluated to assess weaning programs, it should be acknowledged that rumen development may be associated with developmental changes in the small intestine (Górka et al., 2011, 2013) and thus, weaning may influence more regions than the rumen due to changes in nutrient supply and type of nutrient provided, as discussed above. Mannitol, inulin, and Cr-EDTA are markers that have been used to assess GIT permeability. These compounds are nonnutritive and are suggested to cross the GIT via paracellular movement, thus allowing for their use as markers of tissue permeability (Wijtten et al., 2011; Zhang et al., 2013; Penner et al., 2014). Using this approach, Penner et al. (2014) demonstrated that in 6-mo-old calves, susceptibility for movement of mannitol was greatest in the jejunum, whereas movement of inulin was greatest in the omasum followed by the rumen. This suggests that weaning strategies should consider functional changes associated with the entire GIT.

We hypothesized that weaning will negatively affect permeability of the gastrointestinal tract and will involve an increase in permeability in the rumen, omasum, and jejunum. The main objective was to investigate the influence of weaning and age on the permeability of the GIT in calves using in vivo and ex vivo measures of permeability.

\section{MATERIALS AND METHODS}

This experiment was conducted between April and July 2014 at the Livestock Research Building at the University of Saskatchewan (Saskatoon, Saskatchewan, Canada). All procedures used during this experiment were approved by the University of Saskatchewan Research Ethics Board (protocol 20100021).

\section{Animals and Experimental Design}

Fourteen Holstein bull calves were used in a randomized complete block design. Bull calves were obtained from 3 local commercial dairy farms (block) and transported to the research barn within $12 \mathrm{~h}$ of birth. Calves received a commercially available colostrum replacer $(60$ g of IgG, HeadStart, Saskatchewan Colostrum Company, Saskatoon, SK, Canada) on farm and a second dose on arrival at the research barn. Upon arrival, calves received an ear tag and were randomly assigned to 1 of 2 dietary treatments: fed milk replacer and starter until $35 \mathrm{~d}$ of age at which time they were weaned over $7 \mathrm{~d}$ and killed $2 \mathrm{~d}$ postweaning ( $\mathrm{d} 44 ; \mathbf{W N} ; \mathrm{n}=7$ ), or fed milk replacer and starter until d $44(\mathbf{C O N} ; \mathrm{n}=7)$. Calves were housed in individual pens $(1.2 \times 2.4 \mathrm{~m})$ with rubber mats on the floor. Trace amounts of wood shavings were provided to absorb moisture associated with fecal and urine excretion.

After receiving their 2 feedings of colostrum, calves were fed a commercially available milk replacer (Nature's Way 26/16, Landmark Feeds, Winnipeg, MB, Canada; contained $26 \%$ CP, $16 \%$ crude fat, $0.15 \%$ crude fiber, $8 \%$ ash, $0.95 \% \mathrm{Ca}, 0.7 \% \mathrm{P}, 0.7 \% \mathrm{Na}, 40,000 \mathrm{IU} /$ $\mathrm{kg}$ vitamin $\mathrm{A}, 4,000 \mathrm{IU} / \mathrm{kg}$ vitamin $\mathrm{D}_{3}$, and $150 \mathrm{IU} / \mathrm{kg}$ vitamin E) at a rate of $7.5 \%$ of $\mathrm{BW}$ of liquid milk/d (approximately $10.5 \mathrm{~g} / \mathrm{kg}$ of BW, DM basis) for $7 \mathrm{~d}$, and were gradually transitioned to $15 \%$ of BW (approximately $21.1 \mathrm{~g} / \mathrm{kg}$ of BW, DM basis) per day over the next $7 \mathrm{~d}$. Each bag of milk replacer was emptied into a large container and mixed before feeding to minimize variation among feedings, and a 500-g sample was obtained for DM and compositional analysis. Milk was prepared according to the manufacturer's instructions $[150 \mathrm{~g} / \mathrm{L}$; mixed with half the volume of water (45 to $60^{\circ} \mathrm{C}$ ) and whisked for $3 \mathrm{~min}$; then, water was added to bring up to the final volume, resulting in a serving temperature ranging between 38 and $42^{\circ} \mathrm{C}$ ]. Milk was fed by bottle 3 times daily $(0700,1200$, and $1700 \mathrm{~h}$ ) in equal volumes. Calves were given $30 \mathrm{~min}$ to consume each meal and if refusal was greater than $50 \%$ of the meal allotment, the milk replacer was fed via esophageal tube. This approach was used to minimize variation in milk replacer consumption among treatments. Refusals less than $50 \%$ of the meal allotment were removed and the volume was recorded.

Calves were initially offered $100 \mathrm{~g} / \mathrm{d}$ of a commercially available texturized calf starter ration (Optivia Express Calf Starter, Landmark Feeds, Winnipeg, MB, Canada; contained $21.5 \% \mathrm{CP}, 3 \%$ crude fat, $6 \%$ crude fiber, $0.99 \% \mathrm{Ca}, 0.53 \% \mathrm{P}, 0.38 \% \mathrm{Na}, 20.4 \mathrm{kIU} /$ $\mathrm{kg}$ vitamin $\mathrm{A}, 3.3 \mathrm{kIU} / \mathrm{kg}$ vitamin $\mathrm{D}, 95 \mathrm{IU} / \mathrm{kg}$ vitamin $\mathrm{E}$, and $52 \mathrm{mg} / \mathrm{kg}$ sodium monensin). Fresh starter was provided each morning and the provision increased to 
maximum of $500 \mathrm{~g} / \mathrm{d}$ (as fed) for CON. Calves assigned to the WN treatment were provided concentrate for ad libitum consumption. The weight of the refused starter was recorded daily and a daily sample of refusals was collected and used to prepare a weekly composite for each calf. Calves assigned to the $\mathrm{WN}$ treatment were weaned off milk replacer using a 1 step-down weaning process. The weaning process was conducted over $7 \mathrm{~d}$ with the amount of milk reduced from $15 \%$ to $7.5 \%$ of BW before milk provision ceased on d 42. A 500-g sample of starter was also obtained from each bag, frozen and then composited monthly for future compositional and DM analysis.

\section{Blood Sampling and Analysis}

A blood sample was obtained via jugular venipuncture on $\mathrm{d} 7$, and before entering the metabolism crate (d 14, 28, and 44). An additional blood sample was collected at the time of killing (described below). Plasma was collected into heparinized tubes (158 USP units of lithium heparin, BD, Franklin Lakes, NJ) and stored at $4^{\circ} \mathrm{C}$ until centrifuged (within $15 \mathrm{~min}$ ) at $2,500 \times \mathrm{g}$ at $4^{\circ} \mathrm{C}$ for $15 \mathrm{~min}$. Serum was allowed to clot for $15 \mathrm{~min}$ at room temperature before centrifugation. Serum and plasma samples were transferred into vials and stored at $-20^{\circ} \mathrm{C}$ until further analysis.

Plasma glucose and serum BHBA concentrations were analyzed using commercially available kits (Sigma Aldrich, Oakville, ON, Canada, and Roche, Mississauga, ON, Canada, respectively) as previously described by Zhang et al. (2013). Serum insulin concentration was measured in duplicate (coefficients of variations $\leq 10 \%$ ) using a commercially available bovine ELISA kit (Mercodia AB, Uppsala, Sweden).

\section{In Vivo Total-Tract Permeability}

On d 14, 28, and 42, calves were weighed and moved into metabolism crates before the morning feeding. The metabolism crates facilitated the separation and collection of fecal and urinary excretions. In the metabolic crates, calves were provided their milk replacer allocation and then pulse-dosed with $500 \mathrm{~mL}$ of Cr-EDTA (179 $\mathrm{m} M$ Cr-EDTA solution) using an esophageal tube. Calves were kept in crates for $48 \mathrm{~h}$ to facilitate measurement of total urine excretion over 2 consecutive 24-h periods. Zhang et al. (2013) validated the use of Cr-EDTA as an in vivo barrier function measurement and reported that $99 \%$ of the Cr excreted in urine was recovered within $48 \mathrm{~h}$ from the time of dosing. An initial validation was conducted for this study (data not shown) and results corroborated with Zhang et al. (2013). Each day, total urine weight was measured and a $40-\mathrm{mL}$ sample was obtained and frozen at $-20^{\circ} \mathrm{C}$ until being analyzed for $\mathrm{Cr}$ concentration as described by Vicente et al. (2004) using atomic absorption (iCE 3000 series, Thermo Fisher Scientific Inc., Waltham, MA).

\section{Indwelling Rumen pH Measurement}

To evaluate ruminal $\mathrm{pH}$, an orally dosable $\mathrm{pH}$ meter (Penner et al., 2009) was administered on d 32. Calves were restrained in a sitting position as the $\mathrm{pH}$ probe was dosed using a balling gun to facilitate the probe passing over the reticulum and into the rumen. The $\mathrm{pH}$ meters were standardized in standard $\mathrm{pH}$ buffers 4 and 7 and programmed to obtain measurements every $10 \mathrm{~min}$. The $\mathrm{pH}$ meters were collected after killing, at which time data were downloaded and postmeasurement standardization in $\mathrm{pH}$ buffers 7 and 4 completed. Ruminal $\mathrm{pH}$ data were used to calculate the minimum, mean, and maximum $\mathrm{pH}$ values. Measurement of $\mathrm{pH}$ was divided into 3 periods for both $\mathrm{WN}$ and $\mathrm{CON}$ calves: baseline (d 32 to 35), during weaning (d 35 to 42), and postweaning (d 42 to 44 ).

\section{Tissue and Digesta Sampling}

Immediately after obtaining BW, calves were killed via captive bolt stunning, pithing, and exsanguination (d 44) $4 \mathrm{~h}$ after morning feeding. The entire digestive tract was then removed and placed on a table for dissection. Tissues from the rumen (caudal dorsal blind sac), omasum (laminae from the central region), duodenum (proximal to the duodenal colic fold), jejunum (middle point), ileum (proximal to the ileocecal junction), cecum (apical region), proximal colon (end of centripetal turns), and distal colon (midpoint between duodenal colic fold and rectum) were collected and washed by placing a small volume of preheated buffer (Table 1) solution in the lumen followed by gently inverting each end. This process was repeated until the buffer solution appeared to be free of digesta and the mucosal tissues appeared to be clean (approximately 5 to 6 washes). Intestinal tissues were cut longitudinally along the mesenteric connection. Tissues were then placed in an insulated container containing a preheated $\left(38.5^{\circ} \mathrm{C}\right)$ buffer solution ( $\mathrm{pH} \mathrm{7.4;} \mathrm{Table} \mathrm{1)} \mathrm{saturated} \mathrm{with} \mathrm{oxygen}$ (carbogen; $95 \% \quad \mathrm{CO}_{2}: 5 \% \mathrm{O}_{2}$ ) and transported to the laboratory. At the laboratory, tissues were placed in fresh oxygenated buffer. The time from killing to initiation of tissue mounting was less than $45 \mathrm{~min}$.

The digesta from the reticulo-rumen was emptied into a preweighed container to determine mass. A representative sample of rumen fluid was strained through 2 layers of cheesecloth. One sample of ruminal fluid sample was obtained and preserved in ice-cold $25 \%$ 
metaphosphoric acid (wt/vol) for measurement of SCFA concentration and a second sample was collected without an additive. Rumen fluid was then frozen at $-20^{\circ} \mathrm{C}$ until analyzed for SCFA concentration using gas chromatography (Agilent 6890 Series GC system, Agilent Technologies, Mississauga, ON, Canada) as described by Khorasani et al. (1996).

\section{Ex Vivo Measurement of Gastrointestinal Permeability}

Methods for the ex vivo measurement of permeability were conducted according to the methods described by Penner et al. (2014). Briefly, in the laboratory, mucosal segments were carefully prepared by hand stripping (to remove the underlying musculature from the epithelium). For the omasum, laminae from the central region were separated to expose the mucosal and serosal sides. Tissues were then mounted between 2 halves of an Ussing chamber ( $\mathrm{n}=3 /$ region $)$ with an exposed

Table 1. Chemical composition $(\mathrm{m} M)$ of the buffers to prepare tissues and during ex vivo incubations in Ussing chambers

\begin{tabular}{|c|c|c|}
\hline \multirow[b]{2}{*}{ Chemical } & \multicolumn{2}{|c|}{ Buffer solution $^{1}$} \\
\hline & $\begin{array}{l}\text { Glucose- } \\
\text { containing } \\
\text { buffer }\end{array}$ & $\begin{array}{l}\text { SCFA- } \\
\text { containing } \\
\text { buffer }\end{array}$ \\
\hline $\mathrm{CaCl}_{2}$ & 1.8 & 1.8 \\
\hline $\mathrm{MgCl}_{2}$ & 1.0 & 1.0 \\
\hline $\mathrm{NaH}_{2} \mathrm{PO}_{4}$ & 0.5 & 0.5 \\
\hline $\mathrm{KCl}$ & 1.0 & 1.0 \\
\hline $\mathrm{K}_{2} \mathrm{HPO}_{4}$ & 2.0 & 2.0 \\
\hline $\mathrm{NaCl}$ & 92.0 & 92.0 \\
\hline D-Glucose & 5.0 & - \\
\hline Acetic acid & - & 5.0 \\
\hline Na-acetate & - & 13.0 \\
\hline Na-propionate & - & 9.0 \\
\hline Na-butyrate & - & 3.0 \\
\hline Na-gluconate & 25.0 & - \\
\hline Gluconic acid & 5.0 & - \\
\hline HEPES & 5.0 & 5.0 \\
\hline $\mathrm{NaHCO}_{3}$ & 25.0 & 25.0 \\
\hline Inulin & 2.5 & 2.5 \\
\hline Mannitol & 2.5 & 2.5 \\
\hline Penicillin $\mathrm{G},{ }^{2} \mathrm{mg} / \mathrm{L}$ & 60 & 60 \\
\hline Kanamycin sulfate, ${ }^{2} \mathrm{mg} / \mathrm{L}$ & 100 & 100 \\
\hline Flurocytosine ${ }^{2} \mathrm{mg} / \mathrm{L}$ & 50 & 50 \\
\hline Osmolality $^{3}$ & $285.4 \pm 1.24$ & $279.6 \pm 3.54$ \\
\hline
\end{tabular}

${ }^{1}$ The $\mathrm{pH}$ of each buffer was adjusted to 7.4 using $1 M \mathrm{NaOH}$ or 3 $M$ gluconic acid as needed. The glucose-containing buffer was used to prepare tissues immediately after collection, during transport to the laboratory, and during ex vivo incubation in Ussing chambers for the duodenum, jejunum, and ileum tissues. The short-chain fatty acid (SCFA)-containing buffer was used to incubate rumen, omasum, cecum, proximal colon, and distal colon tissues ex vivo in Ussing chambers.

${ }^{2}$ Antibiotics were not included in the buffer used to transport tissue to the laboratory.

${ }^{3}$ Osmolality (mean $\pm \mathrm{SD}$ ) was measured by freezing point depression (model 3250, Advanced Instruments Inc., Norwood, MA). surface area of $3.14 \mathrm{~cm}^{2}$ for rumen and omasal tissues and $1 \mathrm{~cm}^{2}$ for all other tissues. A larger exposed surface area of exposure was used for the rumen and omasal tissues as these tissues appear more heterogeneous than intestinal tissues. The mucosal side of the epithelium was exposed to SCFA buffer for tissues exposed to fermentation in vivo (rumen, omasum, cecum, and colon tissues) and to glucose buffer for tissues that primarily derive their energy from glucose (e.g., small intestinal tissues; Penner et al., 2014; Table 1). All tissues were exposed to the glucose buffer on the serosal side to mimic arterial blood.

Once mounted, tissues were incubated under shortcircuit conditions and tissue conductance was determined every $6 \mathrm{~s}$. All measurements were corrected for the exposed surface area. Once tissues were confirmed to be viable (based on tissue conductance and shortcircuit current), $74 \mathrm{kBq}(20 \mu \mathrm{L} ; 3.7 \mathrm{kBq} / \mu \mathrm{L})$ of ${ }^{14} \mathrm{C}$ mannitol and $148 \mathrm{kBq}(4 \mu \mathrm{L} ; 37 \mathrm{kBq} / \mu \mathrm{L})$ of ${ }^{3} \mathrm{H}$-inulin were added to the mucosal side as described by Penner et al. (2014). Isotopic tracers were allowed to equilibrate for $45 \mathrm{~min}$ before the start of flux measurements. It is important to note that the mucosal and serosal buffers contained the same concentration of mannitol and inulin. The mucosal-to-serosal (MS) flux (J) of mannitol and inulin ( $\mathbf{J}_{\text {MS-mannitol }}$ and $\mathbf{J}_{\mathrm{MS}-\text { inulin }}$, respectively) were determined by measuring the specific activity on the "hot" (mucosal) side and the change in activity on the "cold" side. Thus, at the start of the flux period (45 min after isotope addition), a $100-\mu \mathrm{L}$ sample of buffer was collected from the mucosal side (total buffer volume of $15 \mathrm{~mL}$ ) and placed in a 7 -mL scintillation vial. Subsequently, $400 \mu \mathrm{L}$ of fresh buffer was added to the scintillation vial to equalize volume relative to the cold samples and $5 \mathrm{~mL}$ of scintillation cocktail added (Ultra-Gold, Perkin Elmer, Woodbridge, ON, Canada). Samples of the serosal buffer $(500 \mu \mathrm{L}$ out of a total buffer volume of $15 \mathrm{~mL}$ ) were collected at 45, 105, and 165 min following isotope addition, and scintillation cocktail $(5 \mathrm{~mL})$ was immediately added. An equal volume of fresh buffer solution was added back to the serosal side of the column after each cold sample to minimize changes in hydrostatic pressure. A final hot sample was collected at $165 \mathrm{~min}$ from the mucosal side as described above. After the final hot sample, tissue viability was confirmed by adding $15 \mu \mathrm{M}$ forskolin to both the mucosal and serosal sides and observing the increase in short-circuit current caused by the inhibition of cyclic AMP. Radioactivity was analyzed as decays per minute using a scintillation counter (TriCarb 2910 TR, Perkin Elmer) with a dual-label window to correct for spectral overlap between ${ }^{14} \mathrm{C}$ and ${ }^{3} \mathrm{H}$. All radioactivity measurements were corrected for background radiation using blank buffer samples. 


\section{Statistical Analysis}

Data were analyzed as a randomized complete block design using the MIXED procedure of SAS (version 9.4, SAS Institute Inc., Cary, NC). The model included the fixed effects of dietary treatment and block (farm of origin). For dependent variables that were measured over time, the effect of period and the interaction between treatment and period were included as fixed effects in the model. The period effect was included using a repeated-measures statement, and the covariance structure with the lowest Akaike's and Bayesian information criteria was selected for each variable. Pearson correlations were conducted between preslaughter total Cr-EDTA appearance (measured during d 42 to 44) and inulin and mannitol fluxes measured in Ussing chambers, where the flux rates were the average of the 2 flux periods. For data where there was a significant interaction, means separation was conducted using the Bonferroni correction. Significant differences were determined at $P \leq 0.05$. Data are presented as main effects if nonsignificant and Bonferroni-adjusted $P$-values for significant effects.

\section{RESULTS}

\section{Performance and Feed Intake}

A treatment $\times$ week interaction was observed for BW $(P<0.005)$; however, no differences were detected $(P \geq 0.99)$ despite large numerical differences between $\mathrm{CON}$ and WN calves in wk 5 and 6 (postweaning; Figure 1). As designed, milk replacer intake was affected by a treatment $\times$ week interaction $(P<0.001$; Figure 1) with milk replacer consumption increasing weekly until the week of weaning, where CON calves received more milk replacer $(P=0.001)$ than WN calves. Starter intake was also affected by a treatment $\times$ week interaction $(P<0.001$; Figure 1$)$, with WN calves tending $(P<0.06)$ to have greater starter intake over $\mathrm{CON}$ calves during wk 6 . For ADG, we detected a treatment $\times$ week interaction $(P=0.002$; Figure 1$)$, with $\mathrm{CON}$ calves tending to have a higher ADG $(P=0.06)$ than WN in wk 6 (d 35 to 42 ), which corresponded to the step-down weaning process for WN calves (Figure 1).

\section{Plasma and Serum Metabolites}

Plasma glucose concentration did not differ among treatments except on d 42, when WN calves had a plasma glucose concentration that was $41 \mathrm{mg} / \mathrm{dL}$ lower than that of CON (treatment $\times$ week; $P=0.002$; Figure 2). Similarly, and likely in response to lower energy intake, serum insulin concentration was markedly re- duced (treatment $\times$ week; $P=0.006$ ) for $\mathrm{WN}$ calves on d 42 relative to CON calves (Figure 2). Plasma BHBA concentration was 4.21 and $4.18 \mathrm{mg} / \mathrm{dL}$ (0.155 SEM) for $\mathrm{WN}$ and CON, respectively and did not differ $(P$ $=0.87)$ between treatments, and calves did not differ among weeks $(P=0.56$; data not shown).

\section{Rumen Digesta Mass, SCFA Concentrations, and Rumen $\mathrm{pH}$}

Rumen digesta mass tended ( $P=0.06$; Table 2$)$ to be greater for $\mathrm{WN}$ calves than CON calves. The increase in rumen digesta mass for $\mathrm{WN}$ could be expected given the greater concentrate intake compared with $\mathrm{CON}$. The concentration of SCFA in rumen fluid was approximately $60 \%$ greater $(P=0.029)$ for $\mathrm{WN}$ than for $\mathrm{CON}$ calves. Despite the differences in SCFA concentration, the molar proportions of acetate, propionate, butyrate, and valerate were not affected by treatment $(P \geq$ 0.37 ). However, CON calves had greater proportions of isobutyrate and isovalerate than WN calves $(P \leq$ 0.037), although these SCFA contribute to only a small fraction of the total SCFA.

Minimum, mean, and maximum ruminal $\mathrm{pH}$ values did not differ $(P \geq 0.48$; Table 3$)$ between treatments. When ruminal $\mathrm{pH}$ data were classified into distinct biological periods (i.e., baseline, weaning, and postweaning), average maximum $\mathrm{pH}$ differed by period $(P$ $=0.001$ ), with calves displaying reduced maximum $\mathrm{pH}$ postweaning compared with during the weaning period. In addition, the duration of time that $\mathrm{pH}$ was $<5.5$ increased $(P=0.035)$ from $297 \mathrm{~min} / \mathrm{d}$ during the preweaning period to $573 \mathrm{~min} / \mathrm{d}$ postweaning. We did not detect effects of period $(P=0.50)$ for the area that $\mathrm{pH}$ was $<5.5$ nor were there treatment $\times$ period interactions $(P \geq 0.26)$ for either duration or area that ruminal $\mathrm{pH}$ was $<5.5$.

\section{Gastrointestinal Permeability}

In Vivo Assessment of GIT Permeability. Due to scours, 3 calves from the CON group and 1 calf from WN were not subjected to Cr-EDTA infusion on d 14. A treatment $\times$ period interaction was detected $(P=0.04$; Figure 3$)$ for urinary $\mathrm{Cr}$ excretion, where $\mathrm{Cr}$ excretion in the urine decreased over time, indicating an improvement in barrier function, except for the postweaning measurement. After weaning (d 42 to 44), a differential response was observed for $\mathrm{WN}$ and CON calves: Cr recovery in urine increased for $\mathrm{WN}$ but continued to decrease for $\mathrm{CON}$ relative to that measured on d 28 to 30 . It is important to note that, despite the large numerical difference between treatments dur- 

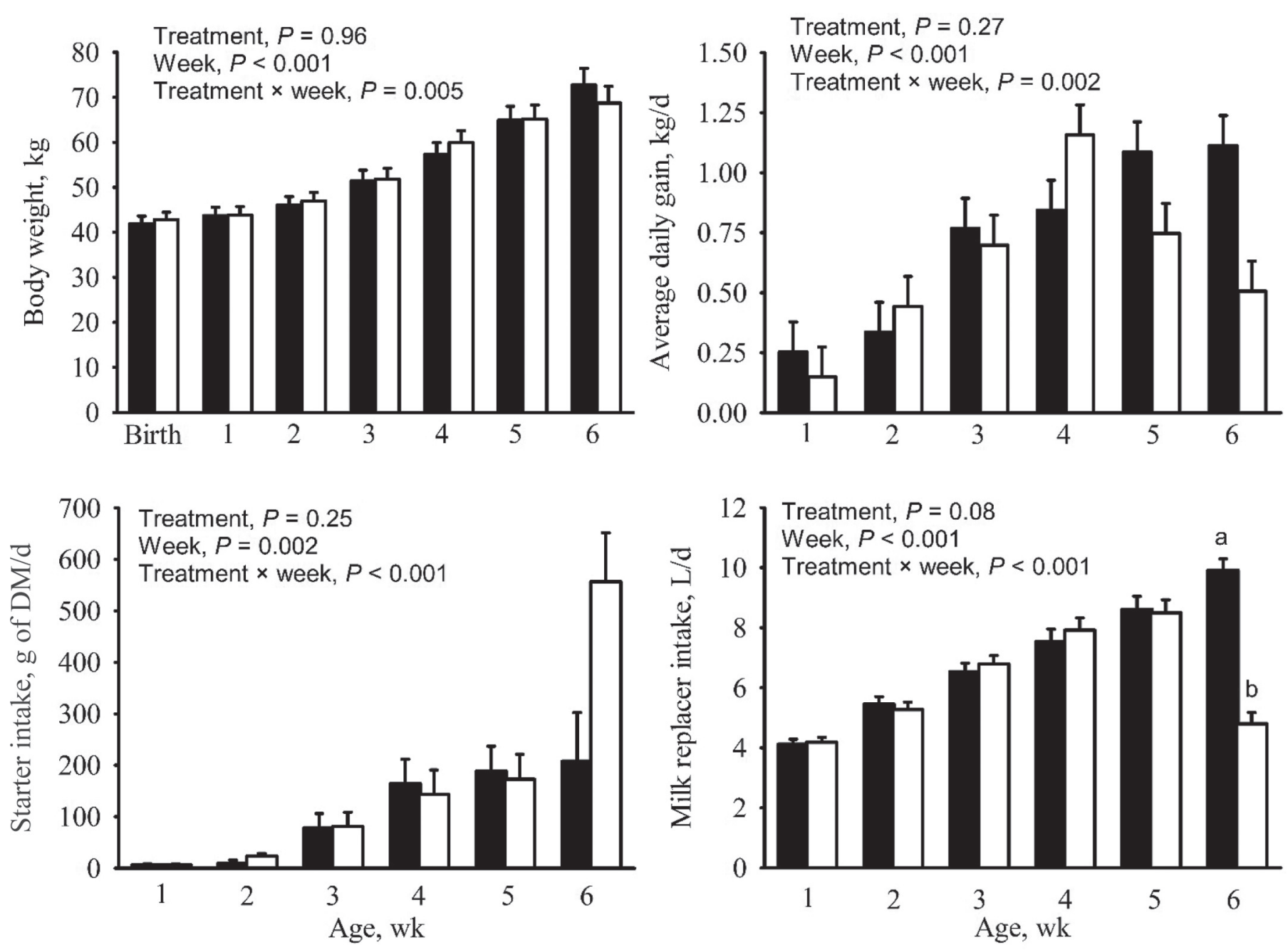

Figure 1. Body weight (top left), ADG (top right), starter intake (bottom left), and milk replacer (bottom right) intake for calves fed milk replacer at a rate of $15 \% \mathrm{BW}(150 \mathrm{~g} / \mathrm{L})$ and not weaned (CON; black columns) or calves exposed to a step-down weaning protocol on d 35 with weaning complete on d 42 (WN; white columns). Columns with different letters at a single time point indicate means that differed based on the Bonferroni means separation $(P<0.05)$. Error bars indicate SEM for the treatment $\times$ week interaction.

ing the measurement occurring over $\mathrm{d} 42$ to 44 , the Bonferroni means separation test did not detect differences between WN and CON $(P=0.28 ; 5.48$ and 43.04 $\mathrm{mg} / 48 \mathrm{~h}$, respectively; $\mathrm{SEM}=9.451)$.

Ex Vivo Assessment of Permeability. The $\mathrm{J}_{\mathrm{MS}-\mathrm{mannitol}}$ and $\mathrm{J}_{\mathrm{MS} \text {-inulin }}$, Gt, and Isc did not differ $(P \geq$ 0.51 ) between dietary treatments (Table 4). However, we observed differences for $\mathrm{J}_{\mathrm{MS}-\text { mannitol }}$ and $\mathrm{J}_{\mathrm{MS} \text {-inulin }}$, tissue conductance $(\mathbf{G t})$, and short-circuit current $\left(\mathbf{I}_{\mathbf{s c}}\right)$ among regions of the GIT (Table 4). For $\mathrm{J}_{\mathrm{MS}-m a n n i t o l}$, flux rate was greater in the rumen than in the ileum, proximal colon, and distal colon, but was not different from that in the duodenum, jejunum, or cecum. For $\mathrm{J}_{\mathrm{MS} \text {-inulin }}$, the rumen had greater flux rates than all tissues except omasum. Flux of inulin was least in the duodenum, jejunum, ileum, and proximal and distal co- lon, and was intermediate for the omasum. We did not detect interactions between treatment and region of the gastrointestinal tract $(P \geq 0.56)$ for either $\mathrm{J}_{\mathrm{MS}-m a n n i t o l}$ or $\mathrm{J}_{\text {MS-inulin. Tissue conductance in the omasum was }}$ less $(P \leq 0.01)$ than that in the jejunum, duodenum, cecum, and proximal and distal colon. Tissue $\mathrm{I}_{\mathrm{sc}}$ was affected by a treatment $\times$ region interaction $(P=0.036)$; however, Bonferroni-corrected values were not different within regions.

\section{DISCUSSION}

The process of weaning induces dramatic adaptations for GIT function as calves are transitioned from a liquidbased diet, which is primarily digested and absorbed postruminally, to a solid-based diet where digestion 
and absorption of nutrients occurs within both pre- and postgastric regions of the GIT. Conventional weaning practices have been designed to ensure that adequate solid feed intake is achieved before the removal of milk or milk replacer as an approach to initiate the adaptive response and maintain adequate nutrient intake (Khan et al., 2011). However, numerous circumstances, such as pathogenic and nutritional insults, may occur during weaning that directly affect feed intake, growth, and performance of the calf (Baldwin et al., 2004). Given the rapid proliferation of the reticulo-rumen and intestinal

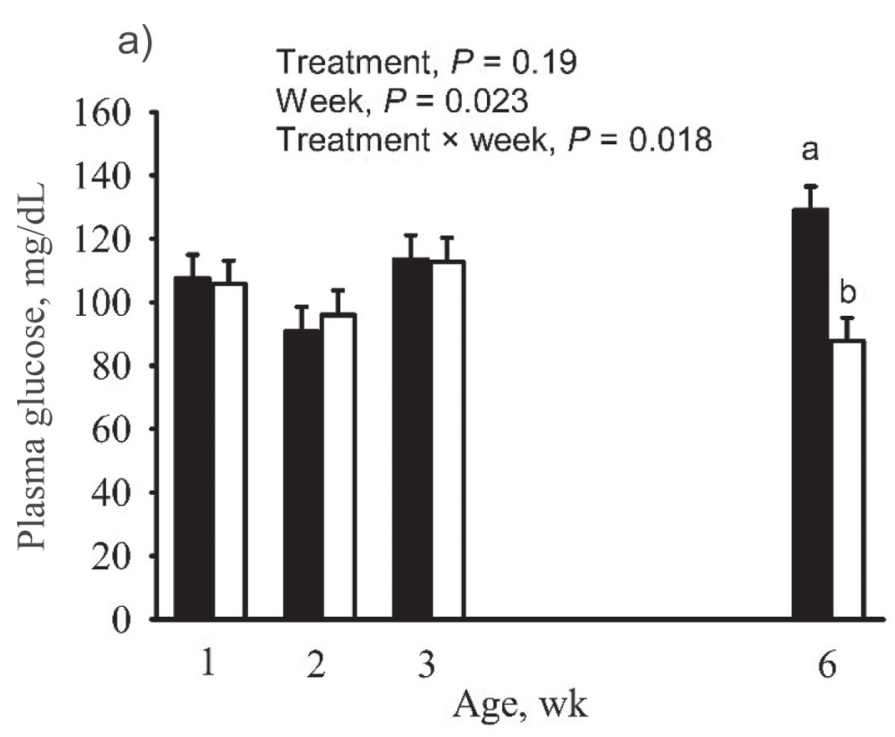

b)

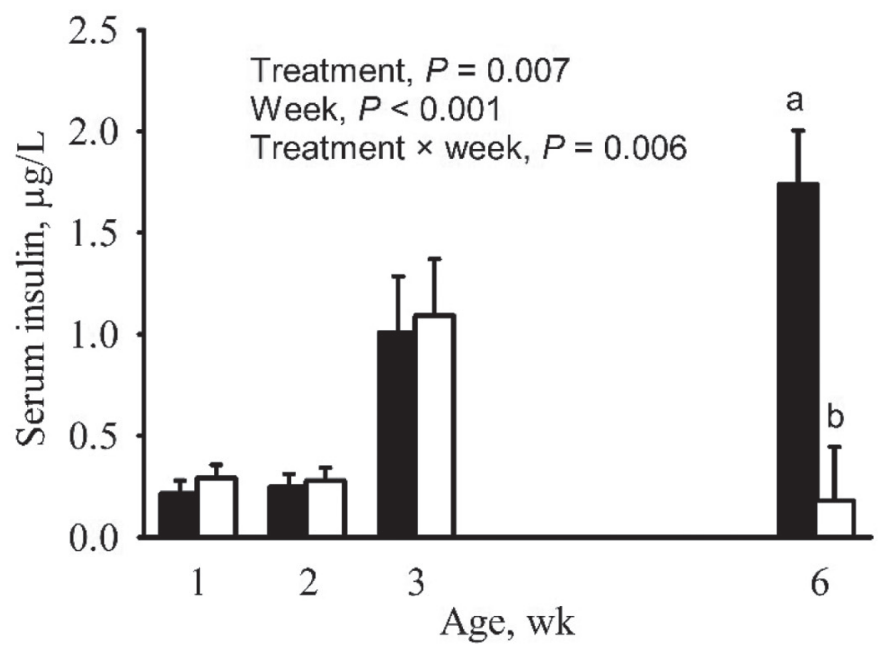

Figure 2. Plasma glucose (a) and serum insulin (b) concentrations for calves fed milk replacer at a rate of $15 \% \mathrm{BW}(150 \mathrm{~g} / \mathrm{L})$ and not weaned (CON; black columns) or calves exposed to a step-down weaning protocol on d 35 with weaning complete on d 42 (WN; white columns). Columns with different letters at a single time point indicate means that differed based on the Bonferroni means separation $(P<$ 0.05). Error bars indicate SEM for the treatment $\times$ week interaction. epithelium (Baldwin et al., 2004), and most likely other regions of the GIT, promoted with the weaning process and the general shift in nutrient substrates and site of digestion, it could be expected that permeability of the GIT may also be modulated by the weaning process.

Generally, nutrients are transported via transcellular processes, which differs markedly from the predominantly paracellular movement of Cr-EDTA, inulin, and inert sugars such as mannitol (Vojdani, 2013). The paracellular pathway is relevant for potential antigens and pathogens; however, given the architecture of tightcell junctions and the presence of receptors that detect molecular-associated microbial patterns (Vojdani, 2013), we are unable to confirm that mannitol, inulin, or Cr-EDTA movement specifically relates to antigen or pathogen translocation. That said, promoting adequate barrier function ensures selective permeability of the GIT to facilitate nutrient absorption while limiting the movement of antigens and pathogens into the lymphatic or portal blood flow. For example, increased permeability may lead to the efflux of nutrients, limiting directional nutrient transport (Gaebel et al., 1989). This may be especially important considering the dramatic changes in microbial community structures that occur with weaning ( $\mathrm{Li}$ et al., 2014a,b). However, to our knowledge, no studies in ruminants have investigated age-dependent changes for barrier function of the GIT and the effect of weaning on barrier function. In the present study, we used permeability as a partial indicator for barrier function and observed that permeability of the GIT was reduced for CON calves with advancing age, suggesting improved barrier function. However, permeability of the GIT for WN calves decreased until weaning was imposed. These data are interpreted to suggest that the weaning process compromised totaltract barrier function and may transiently override the general ontogenic decrease in permeability (i.e., improvement in barrier function).

As mentioned above, we observed an age-dependent reduction in $\mathrm{Cr}$ excretion in urine in response to an oral pulse dose. The use of the indigestible chelates such as Cr-EDTA is a well-established technique for the in vivo measurement of intestinal permeability in monogastrics (Hollander, 1992; Bjarnason et al., 1995; Eutamene et al., 2007) and has recently been validated in ruminants (Zhang et al., 2013). Chromium-EDTA, at least in monogastrics, is not digested or metabolized and has a high renal clearance rate (Bjarnason et al., 1986). In fact, Cr-EDTA is often used to assess renal glomerular filtration rate (Soveri et al., 2014). It has been suggested that Cr-EDTA is not digested in ruminants (Van Soest, 1994). To our knowledge, this is the first study to use this technique in calves as a tool to assess changes occurring over time. Because of the large 
size of Cr-EDTA (11 $\AA$; approximately $340 \mathrm{kDa}$ ), assessing its recovery in the urine provides an indication of paracellular permeability across the gut epithelium (Hollander, 1992; Schweigel et al., 2005). However, as noted by Zhang et al. (2013), the appearance of $\mathrm{Cr}$ in urine provides a generalized indication of permeability but cannot be used to directly indicate the potential for antigen or pathogen translocation based on differences in molecular size and the innate immune responses initiated with detection of microbial-associated molecular patterns.

Our results indicate a reduction in permeability with advancing days of age and an increase in nonspecific permeability induced by weaning, which is supported by previous studies evaluating the weaning response in monogastrics. For example, in rabbit kits (Udall et al., 1981) and hamster pups (David and Harrison, 1984), movement of ${ }^{3} \mathrm{H}-\mathrm{BSA}$ or radioactive heavy metals across the GIT, respectively, decreased with advancing age up to $1 \mathrm{yr}$. These differences are likely attributed to the continuing development of the GIT from birth to after weaning (Henning, 1981). Similar to our study, early weaning in piglets has been shown to reduce barrier function in the small intestine (mid-jejunum) and ascending colon (Moeser et al., 2007). Based on histological analysis, Moeser et al. (2007) reported that weaning reduced mucosal mast cell numbers, which may have implications for the coordination of the intestinal immune response. In addition, piglets that were administered a mast cell activity blocker (cromolyn) via inhibition of tumor necrosis factor- $\alpha$ release (Bissonnette et al., 1995) had mannitol flux across the jejunum that was similar to that of unweaned pigs, whereas untreated weaned piglets had significantly increased mannitol flux. Mast cell counts were similar between milk-fed and weaned cromolyn-treated piglets, suggesting that weaning did not influence mast cell number. A similar trend was observed for colonic tissue. Smith et al. (2010) demonstrated that barrier function increased as weaning age increased from 15 to $26 \mathrm{~d}$ of age, and earlyweaned piglets ( $15 \mathrm{~d}$ of age) also had reduced mucosal mast cell numbers in the jejunum mucosa compared with later-weaned pigs (23 d old; Smith et al., 2010). This indicates that the influence of intestinal mast cells on the immune response cascade may be a key aspect in understanding the gastrointestinal barrier dysfunction. It is unknown whether a similar effect is observed in ruminant jejunum or other intestinal tissues.

The gastrointestinal tract in ruminants is complex, ranging from stratified squamous epithelium in the rumen to simple columnar epithelium within the intestine. Unfortunately, few studies have evaluated how diet or management strategies affect the regional response of the gastrointestinal tract. Malmuthuge et al. (2013) reported that Holstein calves fed a starter ration in combination with milk replacer had greater mRNA expression of claudin-4 in the jejunum and ileum and increased expression of occludin in the jejunum, ileum, and cecum relative to calves fed milk only. The same study suggested that barrier function might be enhanced with consumption of starter intake but these measurements were conducted before weaning. Given the experimental model used in the current study, we are unable to assess the contribution of starter toward GIT permeability but found that weaning increases permeability. Thus, future research is needed to elucidate the relationship between the expression of tight-cell junction proteins at the mRNA and protein levels and functional measurements of permeability associated with weaning and to evaluate persisting effects on barrier function arising from the weaning process. In addition, future studies should include other factors as-

Table 2. Effect of weaning Holstein calves on rumen digesta mass and ruminal short-chain fatty acid (SCFA) concentrations

\begin{tabular}{|c|c|c|c|c|}
\hline \multirow[b]{2}{*}{ Variable } & \multicolumn{2}{|c|}{ Treatment $^{1}$} & \multirow[b]{2}{*}{ SEM } & \multirow[b]{2}{*}{$P$-value } \\
\hline & $\mathrm{CON}$ & WN & & \\
\hline Rumen mass, kg & 1.69 & 2.46 & 0.276 & 0.06 \\
\hline Total SCFA, $\mathrm{m} M$ & 78.1 & 127.4 & 14.37 & 0.029 \\
\hline \multicolumn{5}{|c|}{ Molar proportions, mol/100 mol } \\
\hline Acetate & 47.2 & 48 & 3.23 & 0.85 \\
\hline Propionate & 31.1 & 34.7 & 2.90 & 0.37 \\
\hline Isobutyrate & 0.9 & 0.3 & 0.17 & 0.025 \\
\hline Butyrate & 8.3 & 8.7 & 1.97 & 0.87 \\
\hline Isovalerate & 1.2 & 0.4 & 0.26 & 0.037 \\
\hline Valerate & 2.1 & 2.4 & 0.39 & 0.53 \\
\hline
\end{tabular}




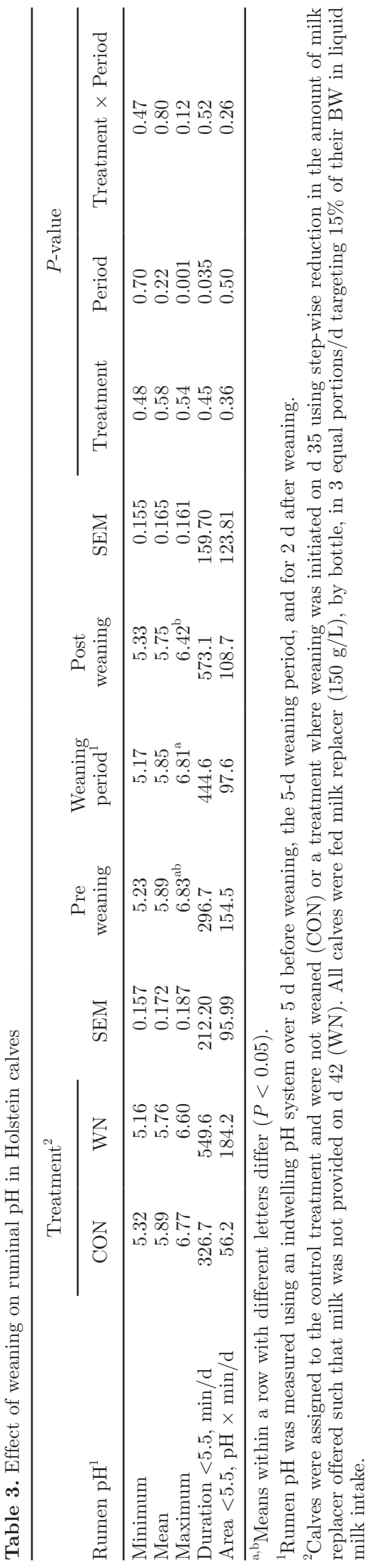

sociated with barrier function, including antimicrobial peptides and microbial-associated molecular pattern receptors.

Although these findings support previous studies evaluating age-dependent changes in permeability and the effect of weaning on GIT permeability (Moeser et al., 2007; Smith et al., 2010), we observed that rumen contents of the CON calves remained purple, indicative of the presence of Cr-EDTA, despite the inability to detect $\mathrm{Cr}$ in urine beyond $48 \mathrm{~h}$. This may be an indication that rumen emptying may have been less in CON calves compared with WN calves and thus, exposure of $\mathrm{Cr}$ to more-distal regions of the GIT may have been reduced. However, visual appearance of $\mathrm{Cr}$ in rumen contents in CON calves beyond $48 \mathrm{~h}$ also implies low epithelial permeability.

Although a negative effect of weaning on permeability of the GIT was detectable using the in vivo Cr-EDTA approach, this approach does not indicate which region or regions of the GIT were affected. To evaluate regional permeability, we used an ex vivo approach (Ussing chambers). Neither a direct treatment difference nor a treatment $\times$ GIT region interaction for permeability measurements was observed. Moreover, we did not detect relationships between the measurements made in vivo and those made ex vivo. The lack of relationship may be explained several ways, including differences in sensitivity among methods, differences due to the size of molecules evaluated (i.e., Cr-EDTA vs. mannitol and

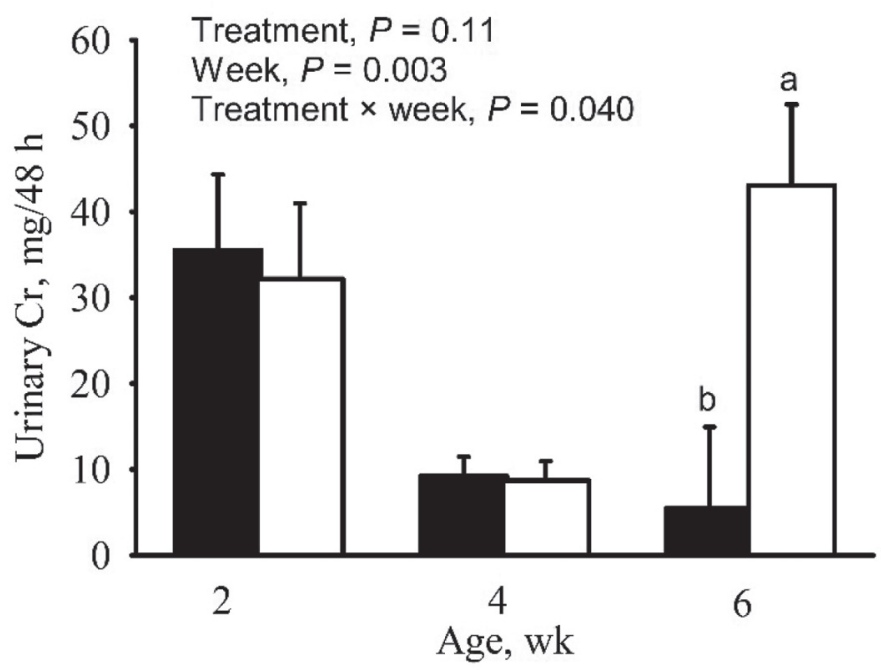

Figure 3. Excretion of chromium in the urine of calves fed milk replacer at a rate of $15 \% \mathrm{BW}(150 \mathrm{~g} / \mathrm{L})$ and not weaned $(\mathrm{CON}$; black columns) or calves exposed to a step-down weaning protocol on d 35 with weaning complete on d 42 (WN; white columns). Columns with different letters at a single time point indicate means that differed based on the Bonferroni means separation $(P<0.05)$. Error bars indicate SEM for the treatment $\times$ week interaction. 
inulin), and potentially that the ex vivo measurements within each region specifically do not account for the relative contribution of each region toward total GIT barrier dysfunction.

Flux rates for both mannitol and inulin were greatest in the rumen, indicating that this region of the GIT may be the most susceptible in calves. Previous work by Penner et al. (2014) also indicated that the jejunum might be a region at risk for high permeability. Using a similar Ussing chamber technique to that in the present study, the jejunum of 6-mo old Holstein calves had the greatest $J_{\text {SM-mannitol }}$, as well as greatest $G_{t}$ of all regions of the GIT. Tissue conductance can be used as an indication of passive ion transfer (Penner et al., 2014). In the present study, we detected no differences between treatments for $G_{t}$, but the results for $G_{t}$ follow similar trends as $\mathrm{J}_{\mathrm{MS}-\text { mannitol }}$ and $\mathrm{J}_{\mathrm{MS} \text {-inulin }}$. Overall, $\mathrm{G}_{\mathrm{t}}$ was highly correlated with $\mathrm{J}_{\text {MS-mannitol }}(P<0.0001 ; \mathrm{r}=0.54$; data not shown). In the present study, measures of $\mathrm{J}_{\mathrm{MS}-\mathrm{mannitol}}$ and $\mathrm{J}_{\mathrm{MS} \text {-inulin }}$ in the jejunum were intermediate relative to those in other regions, but $G_{t}$ was greatest in the jejunum. This suggests that for calves at weaning, the rumen, duodenum, and jejunum may be regions with high permeability and consequently low barrier function.

A potential reason for high permeability in the rumen postweaning could be due, in part, to low ruminal pH (Laarman and Oba, 2011). We observed that maximum ruminal $\mathrm{pH}$ was less postweaning than during the weaning period and the duration that $\mathrm{pH}$ was $<5.5$ increased postweaning relative to that before weaning. These changes correspond to the increase in permeability observed in vivo. Past studies have shown that both low $\mathrm{pH}$ and high osmolarity increase permeability of the ruminal epithelium (Aschenbach and Gäbel, 2000; Penner et al., 2010; Wilson et al., 2012). Moreover, greater dietary proportions, and presumably consumption as in the case of weaning, of rapidly fermentable carbohydrates can induce ruminal acidosis and may increase the concentration of antigens such as lipopolysaccharide in digesta (Gozho et al., 2005; Li et al., 2014a,b), which may also challenge the integrity of the rumen epithelium (Khafipour et al., 2009).

Although there is a paucity of data comprehensively describing rumen $\mathrm{pH}$ changes during weaning, one study comparing calves fed milk replacer with calves fed approximately equal weights of calf starter and milk replacer found no differences in minimum, mean, or maximum rumen $\mathrm{pH}$ and no differences in measures of severity of $\mathrm{pH}$ reduction (duration $\mathrm{pH}<5.8$ or area $\mathrm{pH}$ $<5.8$; Laarman and Oba, 2011). In the present study, the duration that $\mathrm{pH}$ was $<5.5$ was greater postweaning than before weaning. As starter intake also increased overall during this period, this difference in severity of 
rumen $\mathrm{pH}$ likely reflects the increased starter intake and initiation of fermentation in the rumen.

\section{CONCLUSIONS}

Permeability of the GIT decreases with age but weaning can disrupt this process. Moreover, based on the translocation of inulin and mannitol, the rumen, duodenum, and jejunum may be regions with the greatest permeability. This work is some of the first to quantify GIT permeability during weaning in young calves; however, there is a need for future work to improve the understanding of physiological and molecular mechanisms influencing barrier function in calves at and following weaning.

\section{ACKNOWLEDGMENTS}

The authors acknowledge the technical assistance of G. Gratton, R. Kanafany-Guzman, K. Burakowska, R. Pederzolli, B. Weise, F. Joy, and B. Sutherland at the University of Saskatchewan (Saskatoon, Canada) and the input of J. Doelman (Nutreco Canada Inc., Guelph, ON, Canada). Financial support for this project was provided by Nutreco Canada Inc. (Guelph) and the Natural Sciences and Engineering Research Council of Canada ENGAGE program. In addition, S. Palmer was partially supported by a Natural Sciences and Engineering Research Council of Canada Undergraduate Research Assistantship.

\section{REFERENCES}

Aschenbach, J. R., and G. Gäbel. 2000. Effect and absorption of histamine in sheep rumen: Significance of acidotic epithelial damage. J. Anim. Sci. 78:464-470.

Baldwin, R. L. VI, K. R. McLeod, J. L. Klotz, and R. N. Heitmann. 2004. Rumen development, intestinal growth and hepatic metabolism in the pre- and postweaning ruminant. J. Dairy Sci. 87:E55E65.

Bissonnette, E. Y., J. A. Enciso, and A. D. Befus. 1995. Inhibition of tumor necrosis factor-alpha (TNF-alpha) release from mast cells by the anti0inflammatory drug sodium crologlycate and nedocromil sodium. Clin. Exp. Immunol. 102:78-84.

Bjarnason, I., A. MacPherson, and D. Hollander. 1995. Intestinal permeability: An overview. Gastroenterology 108:1566-1581.

Bjarnason, I., T. J. Peters, and A. J. Levi. 1986. Intestinal permeability: Clinical correlates. Dig. Dis. 4:83-92.

David, A. J., and J. D. Harrison. 1984. The absorption of ingested neptunium, plutonium and americium in newborn hamsters. Int. J. Radiat. Biol. Relat. Stud. Phys. Chem. Med. 46:279-286.

Eutamene, H., F. Lamine, C. Chabo, V. Theodorou, F. Rochat, G. E. Bergonzelli, I. Corthésy-Theulaz, J. Fioramonti, and L. Bueno. 2007. Synergy between Lactobacillus paracasei and its bacterial products to counteract stress-induced gut permeability and sensitivity increase in rats. J. Nutr. 137:1901-1907.

Gäbel, G., and J. R. Aschenbach. 2002. Influence of food deprivation on the transport of 3-O-methyl- $\alpha$-D-glucose across the isolated ruminal epithelium of sheep. J. Anim. Sci. 80:2740-2746.
Gaebel, G., M. Bell, and H. Martens. 1989. The effect of low mucosal $\mathrm{pH}$ on sodium and chloride movement across the isolated rumen mucosa of sheep. Q. J. Exp. Physiol. 74:35-44.

Górka, P., Z. M. Kowalski, P. Pietrzak, A. Kotunia, W. Jagusiak, and R. Zabielski. 2011. Is rumen development in newborn calves affected by different liquid feeds and small intestine development. J. Dairy Sci. 94:3002-3013.

Górka, P., P. Pietrzak, A. Kotunia, R. Zabielski, and Z. M. Kowalski. 2013. Effect of method of delivery of sodium butyrate on maturation of the small intestine in newborn calves. J. Dairy Sci. 97:1026-1035.

Gozho, G. N., D. O. Krause, and J. C. Plaizier. 2006. Rumen lipopolysaccharide and inflammation during grain adaptation and subacute ruminal acidosis in steers. J. Dairy Sci. 89:4404-4413.

Henning, S. J. 1981. Postnatal development: Coordination of feeding, digestion, and metabolism. Am. J. Physiol. 241:G199-G214.

Hollander, D. 1992. The intestinal permeability barrier. Scand. J. Gastroenterol. 27:721-726.

Khafipour, E., D. O. Krause, and J. C. Plaizier. 2009. A grain-based subacute ruminal acidosis challenge causes translocation of lipopolysaccharide and triggers inflammation. J. Dairy Sci. 92:10601070.

Khan, M. A., D. M. Weary, and M. A. G. von Keyserlingk. 2011. Invited review: Effects of milk ration on solid feed intake, weaning, and performance in dairy heifers. J. Dairy Sci. 94:1071-1081.

Khorasani, G. R., E. K. Okine, and J. J. Kennelly. 1996. Forage source alters nutrient supply to the intestine without influencing milk yield. J. Dairy Sci. 79:862-872.

Laarman, A. H., and M. Oba. 2011. Short communication: Effect of calf starter on rumen $\mathrm{pH}$ of Holstein dairy calves at weaning. J. Dairy Sci. 94:5661-5664.

Laarman, A. H., A. L. Ruiz-Sanchez, T. Sugino, L. L. Guan, and M. Oba. 2012. Effects of feeding a calf starter on molecular adaptation in the ruminal epithelium and liver of Holstein dairy calves. J. Dairy Sci. 95:2585-2594.

Li, S. C., M. A. Steele, P. Azevedo, M. Carson, J. C. Plaizier, H Derakhshani, and E. Khafipour. 2014a. Development of rumen microbiota in dairy calves: Impact of weaning and different weaning strategies. J. Anim. Sci. 92(E-Suppl. 2):339. (Abstr.)

Li, S. C, M. A. Steele, P. Azevedo, M. Carson, J. C. Plaizier, H. Derakhshani, and E. Khafipour. 2014b. The microbiome composition of the hindgut is altered following weaning in dairy calves: Impact of different weaning strategies. J. Anim. Sci. 92(E-Suppl. 2):314. (Abstr.)

Malmuthuge, N., M. Li, L. A. Goonewardene, M. Oba, and L. L. Guan. 2013. Effect of calf starter feeding on gut microbial diversity and expression of genes involved in host immune responses and tight junctions in dairy calves during weaning transition. J. Dairy Sci. 96:3189-3200.

Moeser, A. J., K. A. Ryan, P. K. Nighot, and A. T. Bilkslager. 2007. Gastrointestinal dysfunction induced by early weaning is attenuated by delayed weaning and mast cell blockade in pigs. Am. J. Physiol. Gastrointest. Liver Physiol. 293:G413-G421.

NAHMS. 2007. Dairy 2007 Heifer calf health and management practices on US dairy operations. USDA Animal and Plant Inspection Service (APHIS), Fort Collins, CO.

NRC. 2001. Nutrient Requirements of Dairy Cattle. 7th rev. ed. National Academies Press, Washington, DC.

Penner, G. B., J. R. Aschenbach, G. Gäbel, and M. Oba. 2009. Epithelial capacity for the apical uptake of short-chain fatty acids is a key determinant of intra-ruminal $\mathrm{pH}$ and the susceptibility to subacute ruminal acidosis in sheep. J. Nutr. 139:1714-1720.

Penner, G. B., J. R. Aschenbach, K. M. Wood, M. E. Walpole, R. Kanafany-Guzman, S. Hendrick, and J. Campbell. 2014. Characterizing barrier function among regions of the gastrointestinal tract in Holstein steers. Anim. Prod. Sci. 54:1282-1287.

Penner, G. B., M. Oba, G. Gäbel, and J. R. Aschenbach. 2010. A single mild episode of subacute ruminal acidosis does not affect ruminal barrier function in the short term. J. Dairy Sci. 93:4838-4845.

Schweigel, M., M. Freyer, S. Leclercq, B. Etschmann, U. Lodemann, A. Bottcher, and H. Martens. 2005. Luminal hyperosmolarity de- 
creases $\mathrm{Na}$ transport and impairs barrier function of sheep rumen epithelium. J. Comp. Physiol. B 175:575-591.

Smith, F., J. E. Clark, B. L. Overman, C. C. Tozel, J. H. Huang, J. E. F. River, A. T. Blisklager, and A. J. Moeser. 2010. Early weaning stress impairs development of mucosal barrier function in the porcine intestine. Am. J. Physiol. Gastrointest. Liver Physiol. 298:G352-G363.

Soberon, F., E. Raffrenato, R. W. Everett, and M. E. Van Amburgh. 2012. Preweaning milk replacer intake and effects on long-term productivity of dairy calves. J. Dairy Sci. 95:783-793.

Soveri, I., U. B. Berg, J. Björk, C. G. Elinder, A. Grubb, I. Mejare, G. Sterner, S. E. Bäck, and SBU GFR Review Group. 2014. Measuring GFR: A systematic review. Am. J. Kidney Dis. 64:411-424.

Udall, J. N., K. Pang, L. Fritze, R. Kleinman, and W. A. Walker. 1981. Development of gastrointestinal mucosal barrier. I. The effect of age on intestinal permeability to macromolecules. Pediatr. Res. 15:241-244.

Van Soest, P. J. 1994. Nutritional Ecology of the Ruminant. 2nd ed. Cornell University Press, Ithaca, NY.
Vicente, F., A. Sarraseca, A. Vega, and J. A. Guada. 2004. Performance of several $\mathrm{Cr}$ and $\mathrm{Yb}$ analytical techniques applied to samples of different biological origin (digesta or faeces). J. Sci. Food Agric. 84:2035-2040.

Vojdani, A. 2013. For the assessment of intestinal permeability, size matters. J. Altern. Ther. Health Med. 19:12-24.

Wijtten, P. J. A., J. van der Meulen, and M. W. A. Verstegen. 2011. Intestinal barrier function and absorption in pigs after weaning: A review. Br. J. Nutr. 105:967-981.

Wilson, D. J., T. Mutsvangwa, and G. B. Penner. 2012. Supplemental butyrate does not enhance the absorptive or barrier functions of the isolated ovine ruminal epithelia. J. Anim. Sci. 90:3153-3161.

Zhang, S., R. I. Albornoz, J. R. Aschenbach, D. R. Barreda, and G. B. Penner. 2013. Short-term feed restriction impairs the absorptive function of the reticulo-rumen and total tract barrier function in beef cattle. J. Anim. Sci. 91:1685-1695. 